\title{
Quarterly inflation rate target and forecasts in Romania
}

\section{Mihaela Simionescu}

Institute for Economic Forecasting of the Romanian Academy, 050711, Bucharest - Romania, Casa Academiei, Calea 13 Septembrie nr.13, sector 5 Habilitated Doctor

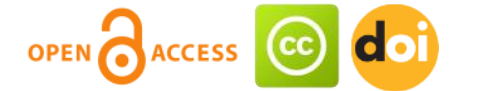

Article history:

Received: October, 2016

1st Revision: October, 2016

Accepted: October, 2016

\section{JEL classification: \\ C51 \\ C52}

DOI:

10.14254/jems.2016.1-1.1

\begin{abstract}
In this study, we proposed some inflation rate predictions based on econometric models that performed better than the targets of the National Bank of Romania. Few econometric models (multiple regressions model and a vector-autoregression) were used to predict the quarterly inflation rate in Romania during 2000:Q1-2016:Q4. The GDP growth has a negative impact on inflation rate in Romania, an increase in logarithm of GDP with one percentage point determining a decrease in inflation logarithm with less than 0.1 units according to both proposed models. However, an increase in inflation rate in the previous period determined an increase in this variable in the current period. The inverse of unemployment rate is positively correlated with the index of prices. The causal relationship between inflation rate and unemployment rate is reciprocal. In the first period the index of prices evolution is explained only by changes in this variable. The inflation rate volatility is due mainly to the evolution of this indicator, the influence decreasing insignificantly in time, not descending under $88 \%$. More than $99 \%$ of the variation in unemployment rate is explained by the own volatility for all lags. The annual forecasts based on these models performed better than the targets on the horizon 2015-2016.
\end{abstract}

Keywords: index of prices, inflation rate, VAR model, unemployment rate.

\section{Introduction}

An important objective of the Romanian monetary authorities is to maintain the inflation rate in a certain target. Before providing forecasts, it is important to know the past evolution of this variable. Falnita and Sipos (2007) proposed a multiple regression model for inflation rate in Romania in the enlarged EU.Damian (2011) studied the disinflation process in Romania within the context of the European integration. The problem of forecasting the inflation rate in the new members of EU was also analyzed by Arratibel, Kamps and Leiner-Killinger (2009). The authors showed that the recent rise in inflation was due to adverse supply shocks, such as energy and food 
price increases, as well as to ongoing changes in the economic structures of these catching-up economies.

The main aim of this study is to propose better annual inflation rate than the official target. We construct several econometric models to explain the evolution of quarterly index of prices, using multiple regression models and a VAR model (vectorial-autoregressive model) The VAR approach allows us to evaluate the variance decomposition of each indicator. In this way, we can determine if the variation in the variable's evolution is mainly due to the other variable or to its own evolution. Woglom (2000) also used VAR model for explaining quarterly inflation that was affected by external shocks in the South Africa in 90's. The author obtained a small linkage between inflation rate and monetary policy. Therefore, the inflation targeting was not recommended for South Africa.

We use as forecast method only simple econometric models, avoiding complex models, because according to Armstrong, Green and Graefe (2015), the golden rule in forecasting is to be conservative. Moreover, for inflation rate in G-7 countries, Canova (2007) showed that the univariate model performed better than the multivariate ones.

Inflation rate is an important macroeconomic indicator used by many institutes in decisionmaking process. The central bank is directly interested by the most accurate inflation rate forecasts in its targeting. Abubakar (2016) made a critical review of the arguments in favour or against inflation targeting in order to ensure the price stability in a country. We consider that inflation targeting is a good tool in establishing the monetary policy, but the values of the targets should be more realistic. Our opinion is also consistent with previous studies in literature of Ball and Sheridan (2004) and Gonçalves and Salles (2008). The authors showed that for emerging countries like Romania, inflation targeting did not succeeded in reducing the inflation volatility. Our solution is not to eliminate the inflation targeting, but to provide better values for targets that take into account the structure of the economy.

The proposal of some targets for inflation to support the monetary policy strategy is an option that was taken into account also by Bernanke and Woodford (1997) who showed the importance to determine if actual policies are consistent with long-term inflation target. The authors showed that the Central Bank might use as inflation targets the predictions of private forecasters, but it also has to take into account the structural model of the economy in order to guide the policy decisions. Moreover, Stein (2015) noticed that the inflation rate expectations are affected by the seasonality of price index that causes deviations in measuring the inflation phenomenon and in predicting it.

In this article, after the methodological approach regarding the inflation modeling, several empirical models are proposed for explaining the quarterly index of prices evolution in Romania during 2000:Q1-2014:Q4.

\section{Modeling inflation rate}

Some studies analyzed the pass-through of external shocks, like shocks in exchange rate, oil price, and non-oil import price to inflation at different stages of distributions. The analysis employed vector-autoregression processes (VAR model) that included the repartition chain of pricing.

More types of models were used to explain the evolution of consumer prices index:

$$
\log \left(I C P_{t}\right)=\alpha_{0}+\alpha_{1} \log \left(I C P_{t-1}\right)+\alpha_{2} \log \left(G D P_{t}\right)+\alpha_{3} \frac{1}{v_{t}}+\varepsilon_{t}
$$

$I C P_{t}$ - index of consumer prices at time $t_{\text {; }}$

$I C P_{t-1}-$ index of consumer prices at time $t$;

$G C P_{t}$ - real gross domestic product at time $t$;

$U_{t}$ - unemployment rate at time $t$;

$\varepsilon_{t}$ - error term;

$\alpha_{0}, \alpha_{1}, \alpha_{2}, \alpha_{3}$ - parameters.

The model is linearized by the introduction of the variable $U^{\prime}$ that is the inverse of the unemployment rate:

$$
\log \left(I C P_{t}\right)=\alpha_{0}+\alpha_{1} \log \left(I C P_{t-1}\right)+\alpha_{2} \log \left(G D P_{t}\right)+\alpha_{3} U_{t}^{\prime}+\varepsilon_{t},
$$


$U_{t}^{\prime}$ - inverse of the unemployment rate at time $t$.

Another econometric model is proposed to explain the price index:

$$
\log \left(I C P_{t}\right)=a 0+a 1 * \log \left(I C P_{t-1}\right)+a 3 * \log \left(G D P_{t}\right)+\varepsilon_{1 t}
$$

a0, a1, a2- parameters;

$\varepsilon_{-} 1$ t- error term.

We consider y_i a vector of " $m$ " variables. Each of these variables has " $p$ " lags. The rest of the variables (the deterministic variables and the constant) are placed in a vector denoted by $y_{* i}$ that has $m^{*}$ elements. The VAR model has the following form:

$$
y_{i}=A(L) y_{i-1}+C y *_{i}+e_{i}, y_{i}=A(L) y_{i-1}+C y *_{i}+e_{i}, e_{i} \rightarrow\left(0, \sum_{e}\right),
$$

Number of regressors: $k=m q+m^{*}$

Number of coefficients: $c=m k$

The VAR model is written in two equivalent forms ( $X$ - a Tk matrix, $Y$ and $E-T m$ matrices, Im- identity matrix, $\alpha-m k$ vector, $y$ and $e-m T$ vectors ):

$$
\begin{gathered}
Y=X A+E \\
\mathrm{y}=(\operatorname{Im} * \mathrm{X}) \alpha+\mathrm{e}, e \rightarrow\left(0, \sum_{e} * I_{T}\right)
\end{gathered}
$$

\section{Econometric models for quarterly inflation}

We start from the relationship between gross domestic product, inflation rate and unemployment rate. Quarterly data were collected for Romania using the data base of National Institute of Statistic and Eurostat, covering the period 2000:Q1-2014:Q4. The data are seasonally adjusted using Tramo/Seats method. In order to ensure the data stationary, some transformations are made to the data. The logarithm was applied to index of consumer prices and real GDP.

The following models were used to explain the evolution of consumer prices index:

$$
\begin{gathered}
\text { M1: } \log \left(I C P_{t}\right)=0.785+0.33 * \log \left(I C P_{t-1}\right)-0.07 * \log \left(G D P_{t}\right)+0.32 * U_{t}^{\prime}+\varepsilon_{t} \\
\mathrm{M} 2: \log \left(I C P_{t}\right)=0.472+0.52 * \log \left(I C P_{t-1}\right)-0.02 * \log \left(G D P_{t}\right)+\varepsilon_{1 t}
\end{gathered}
$$

The errors are independent and homoskedastic. Moreover, we do not have reasons to reject the normal distribution of the errors. The GDP growth has a negative impact on inflation rate in Romania, an increase in logarithm of GDP with one percentage point determining a decrease in inflation logarithm with less than 0.1 units according to both proposed models. However, an increase in inflation rate in the previous period determined an increase in this variable in the current period. The inverse of unemployment rate is positively correlated with the index of prices.

A VAR model is used to explain the price index and unemployment rate evolution in Romania for the same period (2000:Q1-2014:Q4).

The Granger causality test is applied for data series in order to establish if a variable is cause for the other one. In Granger acceptance, a variable $\mathrm{X}$ is cause for $\mathrm{Y}$ if better predictions result when the information provided by $\mathrm{X}$ is taken into account.

The results of Granger causality test show that unemployment rate is the cause of inflation rate and the inflation rate is the cause of unemployment.

Table 1: VAR Granger causality tests
\begin{tabular}{|l|c|c|c|}
\hline Dependent variable: LOG_CPI \\
\hline Exclude & Chi-sq & df & Prob. \\
\hline U & 4.629431 & 2 & 0.0988 \\
\hline All & 4.629431 & 2 & 0.0988 \\
\hline Dependent variable: U & Chi-sq & df & Prob. \\
\hline Exclude & 0.156699 & 2 & 0.9246 \\
\hline LOG_CPI & 0.156699 & 2 & 0.9246 \\
\hline All & & & \\
\hline
\end{tabular}

Source: author's computations 
Almost all the lag length criteria, excepting FPE, at 5\% level indicate that a VAR(2) model is the best model.

\begin{tabular}{|c|c|c|c|c|c|c|}
\hline Lag & $\log L$ & LR & FPE & AIC & SC & HQ \\
\hline 0 & 118.0939 & NA & $2.45 \mathrm{E}-05$ & -4.940166 & -4.861436 & -4.910539 \\
\hline 1 & 139.8430 & 40.72174 & $1.15 \mathrm{E}-05$ & -5.695447 & -5.459258 & -5.606568 \\
\hline 2 & 149.7349 & $17.67914^{*}$ & $8.98 \mathrm{E}-06$ & $-5.976166^{*}$ & $-5.552518^{*}$ & $-5.798034^{*}$ \\
\hline 3 & 153.3040 & 6.075124 & $9.17 \mathrm{E}-06$ & -5.927832 & -5.376724 & -5.720446 \\
\hline 4 & 157.9407 & 7.497505 & 8.97E-06* & -5.954922 & -5.246355 & -5.688283 \\
\hline
\end{tabular}

Source: author's computations

All the tests necessary to be applied for checking the validity of the estimated VAR(2) model are displayed in the following tables. The form of the VAR model is the following:

$$
\begin{gathered}
L O G_{-} C P I=0.2061948594^{*} L O G_{-} C P I(-1)+0.5444928221 * L O G_{-} C P I(-2)-0.00686234259 * U(-1)- \\
0.001448886657^{*} U(-2)+0.003352129141 \\
U=1.539690788^{*} L O G_{-} C P I(-1)-0.6364159519 * L O G_{-} C P I(-2)+0.369408104 * U(-1)- \\
0.1735908506 * U(-2)-0.01830193332
\end{gathered}
$$

VAR Residual Portmanteau Tests are used to test the errors' autocorrelation for both identified model. The assumptions of the test are formulated as:

H0: the errors are not auto-correlated

H1: the errors are auto-correlated

For the lag 1 up to 12, the probabilities (Prob.) of the tests are greater than 0.05 , fact that implies that there is not enough evidence to reject the null hypothesis (H0). So, we do not have enough reasons to say that the errors are auto-correlated. So, after the application of Residual Portmanteau Test, the conclusion is that there are not autocorrelations between errors for VAR(1) model.

Table 3: Residual Portmanteau test for errors auto-correlation
\begin{tabular}{|l|c|c|c|c|c|}
\hline Lags & Q-Stat & Prob. & Adj Q-Stat & Prob. & df \\
\hline 1 & 2.080913 & NA* & 2.124265 & NA $^{*}$ & NA $^{*}$ \\
\hline 2 & 2.218787 & NA* & 2.268007 & NA $^{*}$ & NA $^{*}$ \\
\hline 3 & 4.161288 & 0.3846 & 4.337192 & 0.3623 & 4 \\
\hline 4 & 19.62976 & 0.0118 & 24.18064 & 0.0671 & 8 \\
\hline 5 & 21.92759 & 0.0383 & 25.73959 & 0.0621 & 12 \\
\hline 6 & 23.95599 & 0.0905 & 26.05102 & 0.0533 & 16 \\
\hline 7 & 24.87974 & 0.2061 & 27.12873 & 0.1317 & 20 \\
\hline 8 & 31.40307 & 0.1425 & 34.92490 & 0.0695 & 24 \\
\hline 9 & 33.63316 & 0.2132 & 37.65676 & 0.1051 & 28 \\
\hline 10 & 37.73879 & 0.2234 & 42.81512 & 0.0959 & 32 \\
\hline 11 & 39.15379 & 0.3302 & 44.63972 & 0.1530 & 36 \\
\hline 12 & 43.10263 & 0.3400 & 49.86927 & 0.1363 & 40 \\
\hline
\end{tabular}

Source: author's computations

The homoscedasticity is checked using a VAR Residual LM test for the VAR(1) model. If the value of LM statistic is greater than the critical value, the errors series is heteroskedastic. LM test shows that there is a constant variance of the errors, because of the values greater than 0.05 for the probability. The Residual Heteroskedasticity test is applied in two variants: with cross terms and without cross terms. 


\begin{tabular}{|c|c|c|c|c|c|}
\hline \multicolumn{6}{|c|}{ VAR Residual Heteroskedasticity Tests: No Cross Terms (only levels and squares) } \\
\hline \multicolumn{6}{|c|}{\begin{tabular}{|l|l|l|l|l|} 
Joint test: & & & & \\
\end{tabular}} \\
\hline Chi-sq & df & Prob. & & & \\
\hline 14.29765 & 24 & 0.9396 & & & \\
\hline \multicolumn{6}{|c|}{ Individual components: } \\
\hline Dependent & R-squared & $\mathrm{F}(8,40)$ & Prob. & Chi-sq(8) & Prob. \\
\hline res1*res1 & 0.023433 & 0.119977 & 0.9981 & 1.148224 & 0.9971 \\
\hline res2*res2 & 0.111291 & 0.626138 & 0.7508 & 5.453257 & 0.7082 \\
\hline res2*res1 & 0.147554 & 0.865476 & 0.5530 & 7.230159 & 0.5120 \\
\hline \multicolumn{6}{|c|}{ VAR Residual Heteroskedasticity Tests: Includes Cross Terms } \\
\hline \multicolumn{6}{|c|}{ 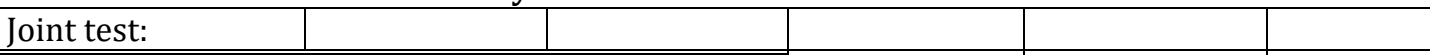 } \\
\hline Chi-sq & $\mathrm{df}$ & Prob. & & & \\
\hline 27.52404 & 42 & 0.9586 & & & \\
\hline \multicolumn{6}{|c|}{ Individual components: } \\
\hline Dependent & R-squared & $\mathrm{F}(14,34)$ & Prob. & Chi-sq(14) & \\
\hline res1*res1 & 0.083264 & 0.220578 & 0.9979 & 4.079929 & \\
\hline res2*res2 & 0.225447 & 0.706878 & 0.7523 & 11.04691 & \\
\hline res2*res1 & 0.244235 & 0.784822 & 0.6777 & 11.96749 & \\
\hline
\end{tabular}

Source: author's computations

The normality tests are applied under the Cholesky (Lutkepohl) orthogonalization. If the Jarque-Bera statistic is lower than the critical value there is not enough evidence to reject the normal distribution of the errors.

Table 5: VAR Residual Normality Tests Orthogonalization: Cholesky (Lutkepohl)
\begin{tabular}{|l|l|l|l|l|}
\hline Component & Skewness & Chi-sq & df & Prob. \\
\hline \hline 1 & 0.134602 & 0.147961 & 1 & 0.7005 \\
\hline 2 & 0.100499 & 0.082484 & 1 & 0.7740 \\
\hline \hline Joint & & 0.230445 & 2 & 0.8912 \\
\hline Component & Kurtosis & & & \\
\hline \hline 1 & 2.916254 & 0.014319 & 1 & Prob. \\
\hline 2 & 2.686947 & 0.200087 & 1 & 0.9048 \\
\hline \hline Joint & & 0.214406 & 2 & 0.6547 \\
\hline & & & df & 0.8983 \\
\hline Component & Jarque-Bera & df & Prob. & \\
\hline \hline 1 & 0.162280 & 2 & 0.9221 & \\
\hline 2 & 0.282572 & 2 & 0.8682 & \\
\hline \hline Joint & 0.444851 & 4 & 0.9786 & \\
\hline \hline
\end{tabular}

Source: author's computations

The Residual normality test provided probabilities greater than 0.05 , fact that implies that the errors series has a normal distribution when Cholesky (Lutkepohl) orthogonalization is applied. The impulse-response analysis and the decomposition of error variance are made. 


\section{Figure 1: The responses of each variable to own shocks or the other variable shocks}

Response to Cholesky One S.D. Innovations \pm 2 S.E.

Response of LOG CPI to LOG_CPI

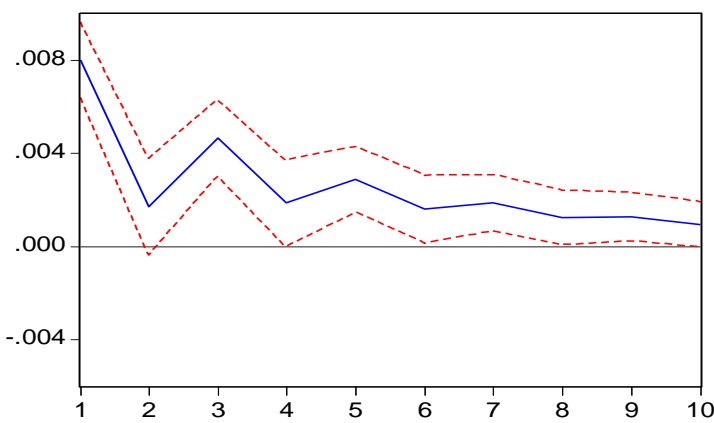

Response of $U$ to LOG_CPI

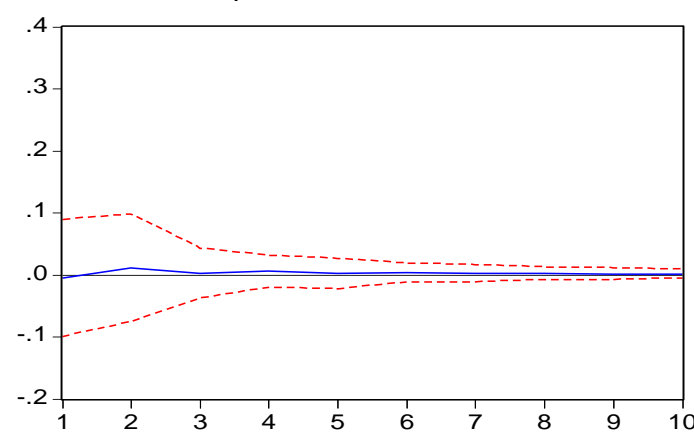

Response of LOG_CPI to $U$

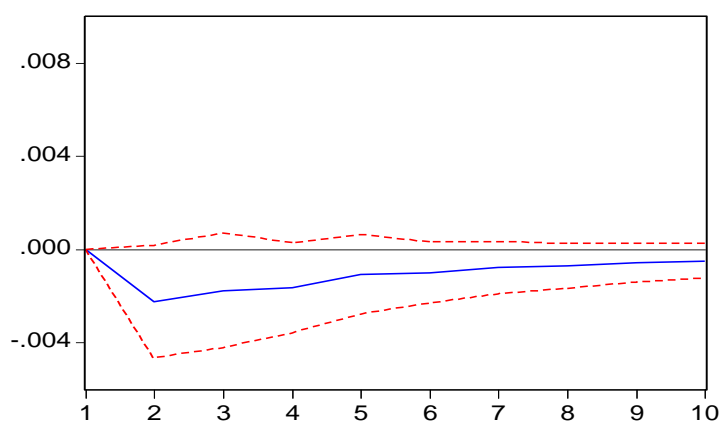

Response of $U$ to $U$

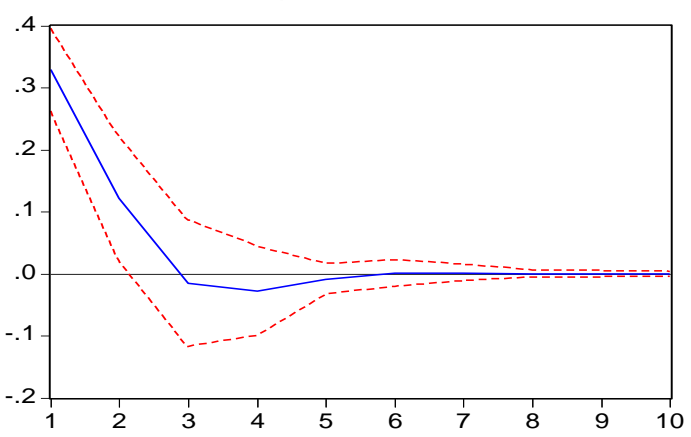

Source: author's graph

In the first period the index of prices evolution is explained only by changes in this variable. The inflation rate volatility is due mainly to the evolution of this indicator, the influence decreasing insignificantly in time, not descending under $88 \%$. More than $99 \%$ of the variation in unemployment rate is explained by the own volatility for all lags.

\section{Table 6: Variance decomposition of the variables}

\begin{tabular}{|l|c|c|c|}
\hline Variance & & Decomposition of LOG_CPI & \\
\hline \hline Period & S.E. & LOG_CPI & U \\
\hline \hline 1 & 0.008015 & 100.0000 & 0.000000 \\
\hline 2 & 0.008497 & 92.94610 & 8.053898 \\
\hline 3 & 0.009849 & 91.49906 & 10.67199 \\
\hline 4 & 0.010158 & 89.32801 & 10.83687 \\
\hline 5 & 0.010614 & 89.16313 & 11.41343 \\
\hline 6 & 0.010781 & 88.58657 & 11.55304 \\
\hline 7 & 0.010971 & 88.44696 & 11.79751 \\
\hline 8 & 0.011064 & 88.20249 & 11.89095 \\
\hline 9 & 0.011151 & 88.10905 & \\
\hline 10 & 0.011201 & 88.00450 & U \\
\hline \hline Variance & & Decomposition of U & 99.96835 \\
\hline \hline Period & S.E. & LOG_CPI & 99.88796 \\
\hline \hline 2 & 0.328925 & 0.031653 & 99.88397 \\
\hline 3 & 0.350792 & 0.112037 & 99.86179 \\
\hline 4 & 0.351150 & 0.116031 & 99.85517 \\
\hline 5 & 0.352316 & 0.136723 & 99.85354 \\
\hline 6 & 0.352437 & 0.138205 & 99.85063 \\
\hline 7 & 0.352450 & 0.144831 & 99.84954 \\
\hline 8 & 0.352454 & 0.146464 & 99.84829 \\
\hline 9 & 0.352460 & 0.149367 & \\
\hline 10 & 0.352463 & 0.150456 & \\
\hline \hline
\end{tabular}

Source: author's computations 
Another application could be the construction of a Bayesian VAR for these two variables. Mester (1998) proposed a VEC model for inflation rate in Romania. The VECM model proved that the basic transmission mechanism runs from base money (via interest rates which affect the relative return on financial assets) to the exchange rate and then to prices.

\section{Inflation rate predictions and targets}

The presented econometric models are used to make quarterly inflation rate for Romania on the horizon 2015:Q1-2016:Q4. The quarterly predictions are aggregated by computing the mean in order to obtain the forecasts for the annual inflation rate. These annual forecasts are compared with the annual targets that are established by the National Bank of Romania.

Table 7: Annual inflation rate forecasts, actual values and targets (\%) (horizon: 2015-2017)

\begin{tabular}{|l|c|c|c|c|c|}
\hline \multirow{2}{*}{ Year } & \multicolumn{3}{|c|}{ Forecasts based on: } & Target & Actual values \\
\cline { 2 - 6 } & M1 model & M2 model & VAR model & & \\
\hline 2015 & 1.2 & 1.1 & 0.9 & 2.5 & -0.6 \\
\hline 2016 & 0.8 & 1 & 0.5 & 2.5 & -1.1 \\
\hline 2017 & 0.8 & 0.9 & 0.33 & 2.5 & - \\
\hline
\end{tabular}

Source: author's computations

The inflation rate predictions and the targets for 2015 and 2016 were evaluated. The forecast error is computed as difference between actual value and predicted value (target).

\begin{tabular}{|c|c|c|c|c|}
\hline \multirow{2}{*}{ Quarter } & \multicolumn{3}{|c|}{ Forecasts based on: } & \multirow[t]{2}{*}{ Target } \\
\hline & M1 model & M2 model & VAR model & \\
\hline 2015 & 1.8 & 1.7 & 1.5 & 3.1 \\
\hline 2016 & 1.9 & 2.1 & 1.6 & 3.6 \\
\hline
\end{tabular}

Source: author's computations

In 2015 and 2016, the VAR model performed better than the multiple regression models in terms of forecast accuracy. Moreover, the targets used by Central Bank were quite far from actual values and from our predictions. In this context, we recommend the use of VAR model predictions in establishing the value of the inflation target in Romania, under the assumption that the historical performance will maintain also in the near future.

\section{Conclusions}

According to this analysis based on VAR model, we can conclude that for the quarterly inflation in Romania during 2000-2015, the causal relationship between inflation rate and unemployment rate is reciprocal.

In the first period the index of prices evolution is explained only by changes in this variable. The inflation rate volatility is due mainly to the evolution of this indicator, the influence decreasing insignificantly in time, not descending under 88\%. More than $99 \%$ of the variation in unemployment rate is explained by the own volatility for all lags. The GDP growth has a negative impact on inflation rate in Romania, an increase in logarithm of GDP with one percentage point determining a decrease in inflation logarithm with less than 0.1 units according to both proposed models. However, an increase in inflation rate in the previous period determined an increase in this variable in the current period. The inverse of unemployment rate is positively correlated with the index of prices.

The proposed models were used to build quarterly inflation rate forecasts. The annual predictions based on these expectations were compared to the targets established by the National Bank of Romania. The results indicated that these predictions based on simple econometric models performed better than the NBR targets. Therefore, the National Bank could fix a more realistic target given by these forecasts.

\section{Appendix A. Supplementary material}

Supplementary data associated with this article can be found, in the online version, at http://dx.doi.org/10.14254/jems.2016.1-1.1 


\section{Funding}

The authors received no direct funding for this research.

\section{Citation information}

Simionescu, M. (2016). Quarterly inflation rate target and forecasts in Romania. Economics, Management and Sustainability, 1(1), 6-13. doi:10.14254/jems.2016.1-1.1.

\section{References}

Abubakar, A. M. (2016). Inflation Targeting as a Monetary Policy Framework: A Critical Appraisal. Imperial Journal of Interdisciplinary Research, 2(6), 1-30.

Armstrong, J. S., Green, K. C., \& Graefe, A. (2015). Golden rule of forecasting: Be conservative. Journal of Business Research, 68(8), 1717-1731. CrossMark: http://crossmark.crossref.org/dialog/?doi=10.1016/j.jbusres.2015.03.031\&domain=pdf.

Arratibel, O., Kamps, C. and Leiner-Killinger, N. (2009). Inflation forecasting in the new EU member states.

Ball, L. M., \& Sheridan, N. (2004). Does inflation targeting matter?. In The Inflation-Targeting Debate (pp. 249-282). University of Chicago Press.

Bernanke, B. S., \& Woodford, M. (1997). Inflation forecasts and monetary policy (No. w6157). National Bureau of Economic Research.

Canova, F. (2007). G-7 inflation forecasts: random walk, Phillips curve or what else? Macroeconomic Dynamics, 11(01), 1-30. doi: http://dx.doi.org/10.1017.S1365100506050334.

Damian, M. (2011). The disinflation process in Romania within the context of the European integration. The USV Annals of Economics and Public Administration, 10(3), 45-54.

Falnita, E., \& Sipos, C. (2007). A multiple regression model for inflation rate in Romania in the enlarged EU.

Gonçalves, C. E. S., \& Salles, J. M. (2008). Inflation targeting in emerging economies: What do the data say? Journal of Development Economics, 85(1), 312-318. doi:10.1016/j.jdeveco.2006.07.002.

Meşter, T. I. (1998). VEC Model of Developing Country Inflationary Dynamics - An Empirical Study - The Case of Romania. Journal of Economics, 24(2), 2.

Stein, R. (2015). Inflation Targeting Rules and Seasonality Bias in Inflation Expectations. Bank of Israel. Retrieved from: http://papers.ssrn.com/sol3/papers.cfm?abstract_id=2688006.

Woglom, G. (2000). Inflation targeting in South Africa: a VAR analysis. Journal for Studies in Economic and Econometrics, 24(2), 1-18. Retrieved from: https://www3.amherst.edu/ grwoglom/Infltargetarticle.doc

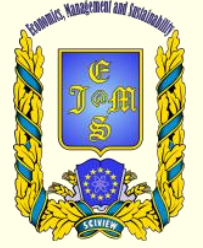

() 2016 Economics, Management and Sustainability. All rights reserved.

This open access article is distributed under a Creative Commons Attribution (CC-BY) 4.0 license.

You are free to:

Share - copy and redistribute the material in any medium or format Adapt - remix, transform, and build upon the material for any

Share - copy and redistribute
purpose, even commercially.

The licensor cannot revoke these freedoms as long as you follow the license terms.

Under the following terms:

Under the following terms:

Attribution - You must give appropriate credit, provide a link to the license, and indicate if changes were made.

You may do so in any reasonable manner, but not in any way that suggests the licensor endorses you or your use.

No additional restrictions

You may not apply legal terms or technological measures that legally restrict others from doing anything the license permits.
}

Economics, Management and Sustainability (ISSN: 2520-6303) is published by Scientific Publishing House "CSR", Poland, EU and Scientific Publishing House "SciView", Ukraine

Publishing with JEMS ensures:

- Immediate, universal access to your article on publication

- High visibility and discoverability via the JEMS website

- Rapid publication

- Guaranteed legacy preservation of your article

- Discounts and waivers for authors in developing regions

Submit your manuscript to a JEMS at http://jems.sciview.net or submit.jems@sciview.net

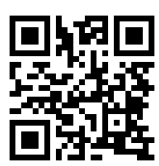

